\title{
Closure of a Difficult-to-Manage Chronic Pressure Injury with the Use of Autologous Platelet-Rich Plasma (APRP)
}

\author{
Gina Xihomara Rojas Mora (D) \\ Jesús Armando Sánchez Godoy (iD) \\ Rodrigo Alberto \\ Heredia Ramirez (iD) ${ }^{2}$ \\ María José Fernández Sánchez (iD) ${ }^{3}$ \\ Lina Andrea Gómez iD ${ }^{4}$ \\ 'Department of Physiological Sciences, \\ School of Medicine, Pontificia \\ Universidad Javeriana, Bogotá, Colombia; \\ ${ }^{2}$ Geriatrics Unit, Hospital Universitario \\ San Ignacio, Department of Internal \\ Medicine, Ageing Institute, Medical \\ School, Pontificia Universidad Javeriana, \\ Bogotá, Colombia; ${ }^{3}$ Department of \\ Internal Medicine, Hospital Universitario \\ San Ignacio, Department of Physiological \\ Sciences, School of Medicine, Pontificia \\ Universidad Javeriana, Bogotá, Colombia; \\ ${ }^{4}$ Bioscience Department, School of \\ Medicine, Biomedical Research Center \\ (CIBUS), Universidad de La Sabana, Chía, \\ Colombia
}

Correspondence: Lina Andrea Gómez Bioscience Department, School of Medicine, Biomedical Research Center (CIBUS), Universidad de La Sabana, Chía, 25000I, Colombia

Tel +57 I 86I 5555

Email lina.gomez3@unisabana.edu.co

\begin{abstract}
Pressure injury (PI) corresponds to a skin damage of ischemic aetiology that affects the integrity of the skin and is produced by prolonged pressure or friction between a hard internal and external surface. Treatment can be challenging when there is no resolution with usual care. The use of autologous platelet-rich plasma (APRP) gel arises as a therapeutic possibility in the presence of chronic pressure injuries. The case of a patient with chronic PI who has been treated with APRP is presented, achieving resolution of the lesion.
\end{abstract} Keywords: pressure ulcer, regenerative medicine, wound healing

\section{Introduction}

Immobility syndrome is defined as a limitation in the ability to perform activities of daily living due to decreased motor functions; it occurs at any age, ${ }^{1}$ but the population over 65 years of age are especially susceptible. ${ }^{2}$ This syndrome increases mortality and morbidity among those who suffer from it. Thus, older adult patients with acute immobility (rapid loss of motor function in less than three days) have a $50 \%$ higher probability of dying in the next six month relative to older adult patients without it. ${ }^{3}$ Similarly, immobility produces physiological alterations in various systems, including the cardiovascular, musculoskeletal and skin system. ${ }^{4}$ Thus, cardiovascular system undergoes several changes such as the appearance of orthostatic hypotension following the decrease in intravascular volume, or an increased risk of thromboembolic disease due to venous stasis. In the musculoskeletal system, immobility produces a progressive decrease in muscle strength, retractions and ankylosis at joint level. ${ }^{3}$ Meanwhile, on the skin system, it is common to find pressure injuries (PI), also known as bedsores or decubitus ulcers, ${ }^{4}$ defined as cutaneous lesions of ischemic aetiology that affect the integrity of the skin and the underlying tissues that are produced by prolonged pressure or friction between an internal and external hard surface. ${ }^{5}$ A tissue such as skin or muscle requires a capillary pressure of $20 \mathrm{mmHg}$ to allow adequate tissue perfusion; a continuous pressure (longer than two hours) greater than $30 \mathrm{mmHg}^{3}$ triggers an ischemic process that can end in necrosis. ${ }^{6}$

It has been found that current prevention techniques may not adequately prevent serious pressure injuries. ${ }^{7}$ Although the best way to avoid the complications of PI is prevention through skin care, proper moisture management, minimizing pressure and attention to the patient's needs, ${ }^{7}$ difficulties in controlling the PI risk factors 
make pressure ulcers a prevalent problem. ${ }^{8}$ Therefore, it is necessary to look for complementary alternatives to conventional PI management to avoid the development of deep or chronic injuries. In the management of similar injuries, innovative strategies related to the field of regenerative medicine have been used, such as the use of platelet rich plasma (PRP). There are a diverse number of studies in the use of PRP for the management of ulcers that have evaluated its efficacy and safety in the management of ulcers in the lower limbs, ${ }^{9-14}$ especially in patients with diabetes. ${ }^{15-18}$ In these patients, PRP promotes and accelerates the healing of chronic diabetic foot ulcers. Thus, PRP helps healing in patients who have had a skin graft rejection or who have comorbidities that contraindicate anaesthetic or surgical procedures. ${ }^{16}$ Similarly, a systematic review and meta-analysis of the management chronic diabetic foot ulcers shows scientific evidence of the use of PRP for the treatment of diabetic ulcers. Their authors claim PRP could be the treatment of choice for the topical care of chronic wounds in diabetic patients. In fact, it is proposed that health services that care for patients with chronic wounds should ensure that any patient who requires it can benefit from the use of PRP. ${ }^{19}$

Based on the biological plausibility of the use of PRP and the favorable evidence of its use in skin lesions, after signing an informed consent, PRP was added to conventional management in a patient who had a chronic ulcer and a high risk to develop a new PI. The treatment was developed in a highly complex hospital in Bogotá that had not yet implemented this management; a recent standardized protocol was used. ${ }^{20}$

\section{Case Report}

A 92-year-old man received hospital care after suffering a left hip fracture. This led to prolonged bed rest of more than a month which led him to develop PI in the left heel. Even though he was treated weekly on an outpatient basis for five months, the PI did not heal. The patient was assessed by the wound clinic of a specialist hospital Bogotá-Colombia for the management of his PI. Norton scale was used to obtain the risk to developing a new PI and the result was 14/20 which corresponded to high risk. The patient had a history of blindness, and he had to use a wheelchair. For this reason, he is limited in his mobility and made him dependent for basic activities. He was considered a candidate for the use of PRP alongside conventional therapy (cleaning, application of zinc oxide, maintenance of dry skin and removal of pressure on the lesion).

\section{Ethics Approval}

This intervention complied with the Declaration of Helsinki, including approval by the institution's Ethics Committee (approval number: FM-CIE-0448-18).

Researchers prepared an informed consent that was approved by the ethics committee of the Pontificia Universidad Javeriana. The patient was blind, we obtained a verbal informed consent from the patient and patient's legal guardian sign the informed consent, for the case details and accompanying images to be published.

\section{Clinical Findings and Therapeutic Intervention}

At the first evaluation, the patient had no coagulation abnormalities, no history of cancer, or the presence of signs of local or systemic infection. Within his paraclinical tests, he presented a hemogram with leukocytes 8,800 / $\mathrm{mm}^{3}$, hemoglobin $14.8 \mathrm{~g} / \mathrm{dL}$, hematocrit $43.5 \%$ platelets $336,000 / \mathrm{mm}^{3}$, creatinine $0.57 \mathrm{mg} / \mathrm{dL}$, albumin $39 \mathrm{~g} / \mathrm{dL}$, all within normal values. Upon admission to the study, a $\mathrm{NUAP}^{5}$ classification Phase II pressure ulcer with thick edges measuring $1.8 \times 3.2 \mathrm{~cm}$ was observed (Figure 1). After the evaluation of the PI, the preparation of autologous platelet-rich plasma (APRP) was carried out as follows: $50 \mathrm{~mL}$ of whole blood was extracted in tubes with sodium citrate, it was centrifuged at room temperature for 10 minutes at a speed of $1,500 \mathrm{rpm}$, according to the previously standardized protocol. ${ }^{20} 8 \mathrm{~cm}^{3}$ of PRP were obtained, which were placed in a Petri dish and $400 \mathrm{mg}$ of calcium gluconate (50 micrograms for each cubic centimeter obtained from PRP), after 25 minutes it was polymerized and applied to the previously cleaned wound. It was covered with a transparent sterile paraffin dressing (Cuticell ${ }^{\circledR}$ Classic) and the patient's family member was instructed to remove it after 72 hours. The wound was evaluated at 7 days (Figure 2); the same treatment was repeated once a week for a total of four sessions. During treatment researchers observed that after the first week there was a slow decrease in the percentage of closure of the PI, but that after 15 days a closure greater than $50 \%$ was achieved and after the third application and evaluation after 24 days, the closing was greater than $90 \%$ (Figure 3). Finally, at the fifth week, the PI was evaluated, showing changes in the diameter of the wound of $0.5 \times 1.2 \mathrm{~cm}$, 


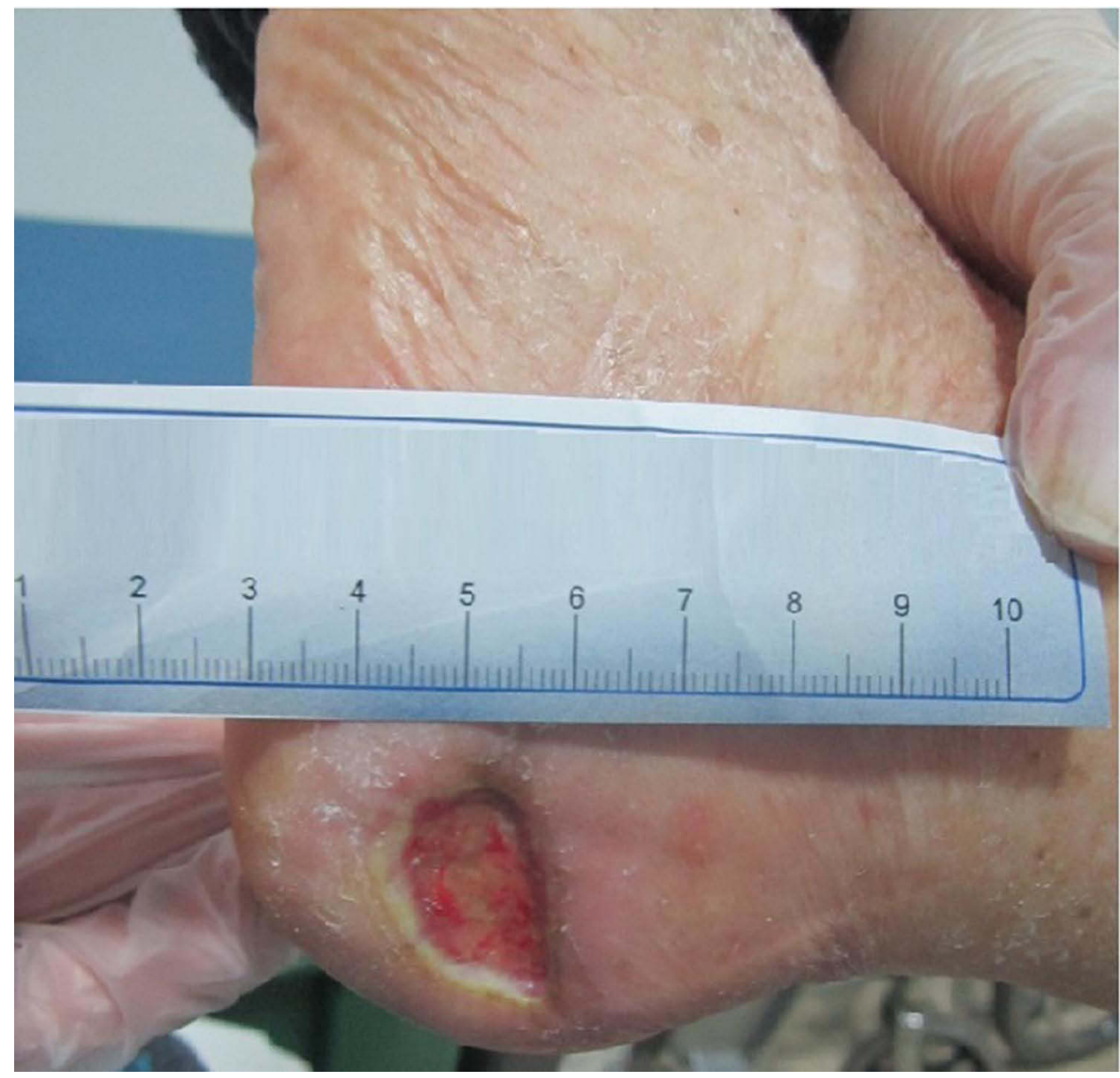

Figure I Injury at the beginning of the study day 0 .

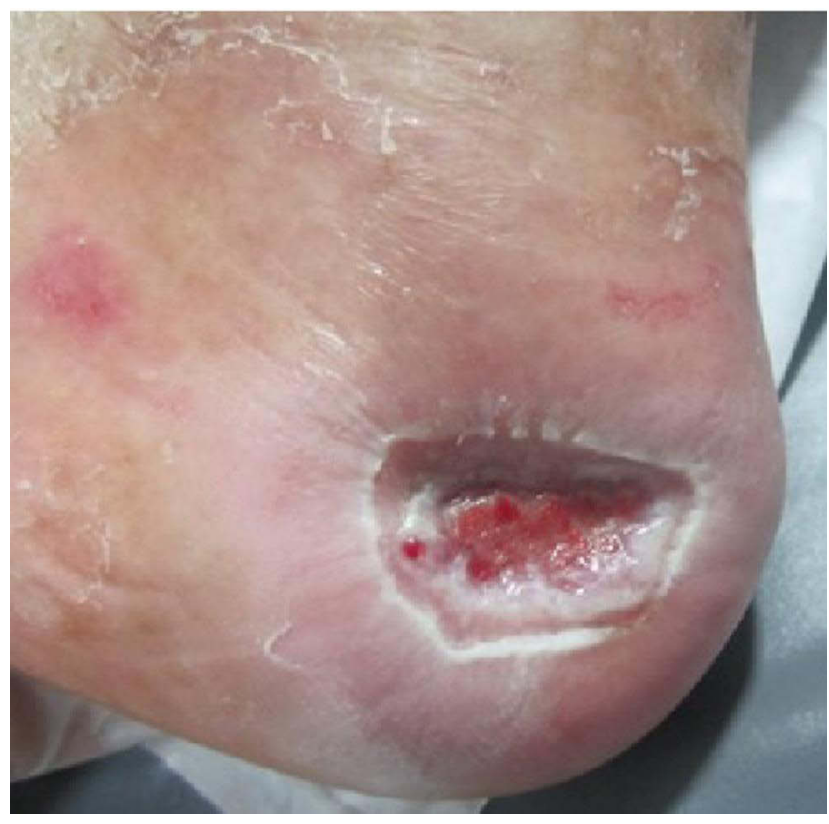

Figure 2 Visit 8 days after the first application of APRP. without signs of infection or discharge (Figure 4). The wound continued to receive normal healing during the following weeks and after another month of treatment the wound closed completely.

\section{Discussion}

PI have an increasing prevalence and incidence ${ }^{21}$ due to the increase in life expectancy ${ }^{22}$ and disability in the general population. ${ }^{23}$ Furthermore, PI tend to be wounds that are difficult to heal, which makes them the focus of infectious $^{24}$ or chronic inflammatory processes, a source of morbidity and even mortality in populations that remain immobile for various reasons. This leads to poor quality of life, social isolation, emotional stress and depression in patients who suffer from them, ${ }^{25}$ as well as significant economic repercussions. ${ }^{26}$ The prevention of these injuries is the best alternative to avoid these complications and costs. $^{27}$ However, even with the use of devices with 


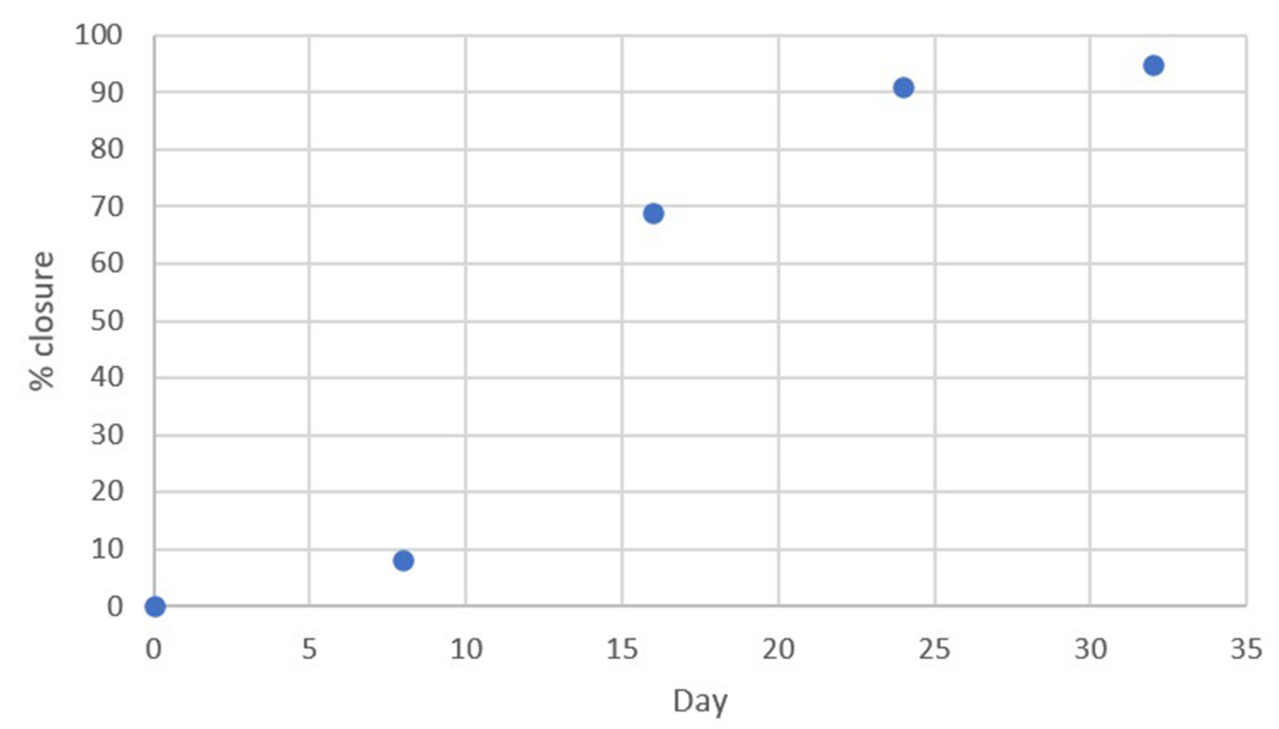

Figure 3 Evolution of the patient's PI, percentage of closure versus time (days).

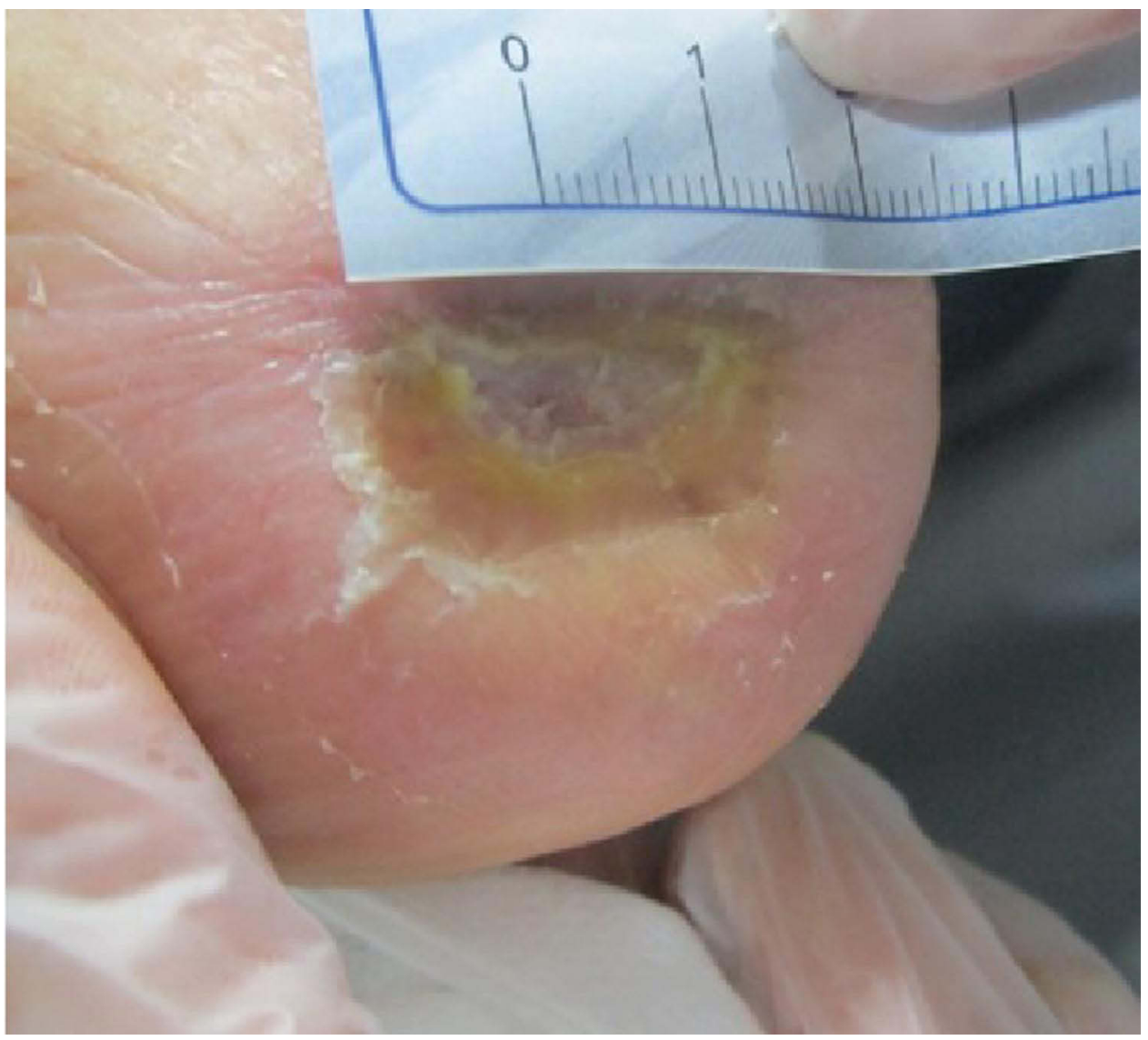

Figure 4 Assessment 32 days after starting the protocol.

specialized static surfaces ${ }^{28}$ and rigorous protocols for their prevention, it is not possible to avoid them in $100 \%$ of patients who are at risk of suffering them. ${ }^{29,30}$ Thus, once they arise, it is necessary to use effective alternatives to speed up healing. Debridement, position changes, nutritional optimization, treatment of underlying infections and control of spasms have been postulated as essential in its management. ${ }^{31}$ However, it is also important to seek 
complementary, innovative and effective alternatives that reduce healing time, hospital stay ${ }^{32}$ and associated costs.

The healing of ulcers, especially chronic ones, is dependent on growth factors. The therapeutic administration of growth factors topically, associated with conventional preventive measures, has the potential to accelerate the healing of these wounds. ${ }^{33}$ Thus, APRP, a treatment that contains fibrin and high concentrations of growth factors, is an option that has shown potential in preliminary studies to help the healing of these wounds. ${ }^{34,35}$

PRP has been widely used in clinical practice in various tissue disorders. However, there is a little evidenced to suggest the routine use of the PRP in pressure ulcers. ${ }^{36}$ This fact is consistent with the proposals of some government bodies, such as the Spanish Agency for Medicines and Health Products, which encourage researchers to carry out properly designed clinical trials to establish adequate levels of evidence in each of the pathologies that merit the use of $\mathrm{PRP}^{37}$ or with the conclusions of some systematic reviews regarding the need for randomized clinical trials to evaluate the use of PRP in wound management. ${ }^{38}$

Currently, there are not a significant number of publications related to the use of PRP in PI or studies in the management of other types of ulcers and in the general management of both acute and chronic wounds. In animals, the efficacy of this intervention in wound healing has been evaluated with favourable results. ${ }^{39-42}$ Histological techniques have revealed that through the application of PRP products, neovascularization is significantly increased. $^{39-43}$ Similarly, compared to the controls, PRP significantly improves the formation of granulation tissue, a key element in wound healing. ${ }^{40,42,43}$ In vitro studies have shown that PRP induces endothelial cell proliferation and capillary formation, as well as increasing fibroblast proliferation compared to the controls in different therapeutic concentrations. ${ }^{40,43,44}$

Analyses have been carried out on various species. For example, the potential of platelet-derived growth factors to improve surgical wound healing has been evaluated in horses, showing that wounds treated with a PRP gel present rapid epithelial differentiation and greater organization of dermal collagen in comparison with controls. ${ }^{45}$ Other studies have included stem cells in addition to PRP, this is the case of an investigation where the treatment of severe decubitus ulcers was performed with mesenchymal cells from amniotic fluid and PRP gel in a new born septic foal. ${ }^{46}$ Plasma rich in growth factors has been evaluated in the healing of skin wounds in albino rabbits, which showed an acceleration in epithelialization and a reduction in skin inflammation at 7 days. ${ }^{47}$ Similar studies have been carried out in epidermal wounds in rabbit ears with intralesional injection of PRP with convenient results regarding healing. ${ }^{48}$

In humans, the efficacy and safety of the use of PRP in PI is limited. It is suggested that treatment with growth factors derived from platelets (obtained from PRP) benefit the healing of these lesions and has a potential antibacterial effect. However, the same authors state the need for more studies to support these findings. ${ }^{49}$ Many of the studies have arisen thanks to the growing trend of applying APRP for the treatment of acute and chronic inflammatory processes, ${ }^{9-}$ 11,50 as in the treatment of soft tissue lesions of the musculoskeletal system. ${ }^{51,52}$ In 1982, a pioneering investigation was published on the use of a fibrin gum, using Platelet Poor Plasma in the repair of a peripheral nerve. ${ }^{53}$

Since then, especially in the last two decades, these therapies have been used as the main or complementary treatment in different pathologies. APRP is applied topically to the wound or as a local or intra-articular injection. It has been used with appropriate evidence in orthopedics; in the treatment of chronic tendinopathies, ${ }^{54}$ in dentistry; in post-dental extraction healing and ossification, ${ }^{55,56}$ in plastic surgery; to improve the healing of lower limb ulcers, ulcers in patients with diabetes and bone grafts.$12,38,50,57$ Recently, a study using negative pressure wound therapy plus PRP gel found an acceleration in ulcer closure times related to patients with refractory treatment. ${ }^{36}$ These findings indicate the use of PRP as the treatment of choice for the topical care of chronic wounds. In fact, it is proposed that health services that care for patients with chronic wounds should ensure that any patient who requires it can benefit from the use of PRP. ${ }^{19}$

The studies cited above motivated the team of the ulcer clinic of a university hospital in Bogotá to implement the use of APRP to close a PI that had not developed satisfactorily with conventional management. The experience of using APRP in this patient was very satisfactory. Even though the PI had received a usual treatment for 5 months never close and after a month of management with APRP, a closure of $95 \%$ was obtained. During the intervention and follow-up time, no signs of an allergic reaction or infection were observed. The patient and his caregivers reported having adequately tolerated the handling. Likewise, the members of the Wound Clinic care team stated that the technique of preparation and application of the gel was easy and fast. 
Easy application, minimal pain and low cost were evidenced as advantages of using APRP. The preparation and application of the APRP is simple because it consists of few steps and can be learned easily. It is a low-cost technique, once you have the infrastructure that involves a biological safety cabinet and a centrifuge, the rest of the materials such as needles, blood collection system, Petri dish and calcium gluconate, plus the materials used in a regular dressing (gauze, zinc oxide, sterile water or saline solution) are inexpensive. On the other hand, pain is associated with a puncture to obtain plasma but there is no pain when applying the gel. Finally, by accelerating the healing process, patient satisfaction is obtained by achieving the closure of a lesion that affects their quality of life.

APRP is an innovative strategy as an alternative to difficult-to-manage lesions; however, success in this patient may be associated with factors other than APRP, such as the PI phase, the production of growth factors itself, or their nutritional condition. The PI in phase II and III with granulation tissue are in the proliferative phase of healing, in this phase there are numerous growth factors and processes such as angiogenesis and fibroblast migration, which accelerates the process of healing compared to PI in more advanced stages. ${ }^{58}$ Additionally, biological differences between individuals are a facet that is related to the amount of growth factors and the activation of these factors, which can contribute to the speed of closure of the lesion. Likewise, the patient's nutrition could be indirectly correlated with their albumin levels. Therefore, since it is a single case, it is difficult to predict whether the improvement of the lesion is only secondary to the use of APRP or the various factors mentioned here.

\section{Conclusions}

PI are a problem of increasing prevalence and incidence, a situation that affects the quality of life of patients and incurs excessive costs on the health system. Sometimes these lesions do not respond to conventional management and become chronic. Thus, it is necessary to offer effective and safe alternatives that promote lesion closure. Among these alternatives is the use of APRP, which has shown benefits in tissue regeneration, both in animal models and in humans. However, although it has been used clinically for various types of injuries, the experience of the use of PRP is limited in PI. This report shows a positive experience of the use of PRP in a patient with an PI who had not had a satisfactory evolution with conventional management. Given the efficacy in wound closure and the absence of adverse effects, the use of PRP is considered a promising therapy for the management of chronic PI in the outpatient or hospital setting.

Given that it is the experience of a single patient, studies with a greater number of individuals and different types of PI are required, and allow to evaluate the efficacy and safety of the treatment and, thus, reach enough evidence to consider the use of PRP as part of the usual handling of PI.

\section{Abbreviation}

APRP, autologous platelet-rich plasma

\section{Acknowledgments}

The authors thank the Universidad Javeriana and the Hospital San Ignacio for the financial support (Investigation project ID: 6223 - Conv. HUSI-PUJ). We also appreciate the financial support to the Universidad de la Sabana (Project ID: MED-247-2018).

\section{Disclosure}

Dr Armando Sánchez report grants from Hospital Universitario San Ignacio, during the conduct of the study. Dr Rodrigo Alberto Heredia Ramirez report grants from Hospital Universitario San Ignacio, during the conduct of the study. Dr María José Fernandez Sánchez report grants from Hospital Universitario San Ignacio, during the conduct of the study. The authors report no other conflicts of interest in this work.

\section{References}

1. Urso ML, Clarkson PM, Price TB. Immobilization effects in young and older adults. Eur $J$ Appl Physiol. 2006;96(5):564-571. doi:10.1007/s00421-005-0109-1

2. Fierro A, Solari PS, Pérez A. Síndrome de Inmovilidad. Rev Tendencias Médicas. 2015;2(47):73-76.

3. González Madrigal LN. Síndrome de inmovilización en el adulto mayor. Rev Medica Costa Rica Y Centroam. 2015;LXXI(616):551-555.

4. Rousseau P. Immobility in the aged. Arch Fam Med. 1993;2(2):169177. doi:10.1001/archfami.2.2.169

5. Black J, Baharestani M, Cuddigan J, et al. National pressure ulcer advisory Panel's updated pressure ulcer staging system. Dermatol Nurs. 2007;19(4):343-350.

6. Salazar CA, Duque OF, Moreno B. Ulceras por presión. In: Gerontología SEdGy, ed. Tratado de Geriatía Para Residentes. Coordinación editorial: International Marketing \& Communication, S.A. (IM\&C) Vol. 1. 2017:217-226.

7. Kayser SA, VanGilder CA, Lachenbruch C. Predictors of superficial and severe hospital-acquired pressure injuries: a cross-sectional study using the international pressure ulcer prevalence ${ }^{\mathrm{TM}}$ survey. Int J Nurs Stud. 2019;89(September2018):46-52. doi:10.1016/j.ijnurstu.2018.09.003

8. Delmore B, Ayello EA, Smith D, Rolnitzky L, Chu AS. Refining heel pressure injury risk factors in the hospitalized patient. Adv Ski Wound Care. 2019;32(11):512-519. doi:10.1097/01.ASW.0000579704.28 027.d2 
9. Kim DH, Kim JY, Seo SH, Ahn HH, Kye YC, Choi JE. Recalcitrant cutaneous ulcer of comorbid patient treated with platelet rich plasma: a case report. $J$ Korean Med Sci. 2012;27(12):1604-1606. doi:10.3346/jkms.2012.27.12.1604

10. Cervelli V, Gentile P, De Angelis B, et al. Application of enhanced stromal vascular fraction and fat grafting mixed with PRP in posttraumatic lower extremity ulcers. Stem Cell Res. 2011;6(2):103-111. doi:10.1016/j.scr.2010.11.003

11. Salemi S, Rinaldi C, Manna F, Guarneri GF, Parodi PC. Reconstruction of lower leg skin ulcer with autologous adipose tissue and platelet-rich plasma. J Plast Reconstr Aesthet Surg. 2008;61 (12):1565-1567. doi:10.1016/j.bjps.2008.04.048

12. Rozman P, Bolta Z. Use of platelet growth factors in treating wounds and soft-tissue injuries. Acta Dermatovenerol Alp Panonica Adriat. 2007;16(4):156-165.

13. Bernuzzi G, Tardito S, Bussolati O, et al. Platelet gel in the treatment of cutaneous ulcers: the experience of the Immunohaematology and Transfusion Centre of Parma. Blood Transfus. 2010;8(4):237-247. doi:10.2450/2009.0118-09

14. Ramos-Torrecillas J, De Luna-bertos E, García-Martínez O, DíazRodríguez L, Ruiz C. Use of platelet-rich plasma to treat pressure ulcers: a case study. J Wound Ostomy Continence Nurs. 2013;40 (2):198-202. doi:10.1097/WON.0b013e318280018c

15. Scimeca CL, Bharara M, Fisher TK, Kimbriel H, Armstrong DG. Novel use of platelet-rich plasma to augment curative diabetic foot surgery. J Diabetes Sci Technol. 2010;4(5):1121-1126.

16. Saad Setta H, Elshahat A, Elsherbiny K, Massoud K, Safe I. Plateletrich plasma versus platelet-poor plasma in the management of chronic diabetic foot ulcers: a comparative study. Int Wound J. 2011;8(3):307-312. doi:10.1111/j.1742-481X.2011.00797.x

17. Shan G-Q, Zhang Y-N, Ma J, et al. Evaluation of the effects of homologous platelet gel on healing lower extremity wounds in patients with diabetes. Int J Low Extrem Wounds. 2013;12(1):2229. doi: $10.1177 / 1534734613477113$

18. Tzeng Y-S, Deng S-C, Wang C-H, Tsai J-C, Chen T-M, Burnouf T. Treatment of nonhealing diabetic lower extremity ulcers with skin graft and autologous platelet gel: a case series. Biomed Res Int 2013;2013:837620. doi:10.1155/2013/837620

19. Villela DL, Santos VLCG. Evidence on the use of platelet-rich plasma for diabetic ulcer: a systematic review. Growth Factors. 2010;28(2):111-116. doi:10.3109/08977190903468185

20. Gómez LA, Escobar M, Peñuela O. Standardization of a protocol for obtaining platelet rich plasma from blood donors; a tool for tissue regeneration procedures. Clin Lab. 2015;61(8):973-980.

21. VanGilder C, Amlung S, Harrison P, Meyer S. Results of the 2008-2009 International Pressure Ulcer Prevalence Survey and a 3year, acute care, unit-specific analysis. Ostomy Wound Manage. 2009;55(11):39-45.

22. Neziraj M, Hellman P, Kumlien C, Andersson M, Axelsson M. Prevalence of risk for pressure ulcers, malnutrition, poor oral health and falls - a register study among older persons receiving municipal health care in southern Sweden. BMC Geriatr. 2021;21(1):1-10. doi:10.1186/s12877-021-02205-x

23. Jaul E. Who determines the treatment for pressure ulcers in the elderly? Isr Med Assoc J. 2013;15(9):512-515.

24. Eilers R, Veldman-Ariesen MJ, Haenen A, van Benthem BH. Prevalence and determinants associated with healthcare-associated infections in long-term care facilities (HALT) in the Netherlands, May to June 2010. Euro Surveill. 2012;17(34):1-8.

25. Jones D. Pressure ulcer prevention in the community setting. Nurs Stand. 2013;28(3):47-55. doi:10.7748/ns2013.09.28.3.47.e7660

26. Schuurman J, Schoonhoven L, Defloor T, van Engelshoven I, van Ramshorst B, Buskens E. Economic evaluation of pressure ulcer care: a cost minimization analysis of preventive strategies. Nurs Econ. 2009;27(6):390-400.
27. Pham B, Teague L, Mahoney J, et al. Early prevention of pressure ulcers among elderly patients admitted through emergency departments: a cost-effectiveness analysis. Ann Emerg Med. 2011;58 (5):468-78.e3. doi:10.1016/j.annemergmed.2011.04.033

28. McInnes E, Jammali-Blasi A, Bell-Syer SE, Dumville JC, Cullum N. Support surfaces for pressure ulcer prevention. Cochrane Database Syst Rev. 2011;4:CD001735. doi:10.1002/14651858.CD001735.pub4

29. Chou R. Pressure ulcer risk assessment and prevention. Ann Intern Med. 2013;159(10):718-719. doi:10.7326/0003-4819-159-10201311190-00017

30. van Rijswijk L, Beitz JM. Creating a pressure ulcer prevention algorithm: systematic review and face validation. Ostomy Wound Manage. 2013;59(11):28-40.

31. Cushing CA, Phillips LG. Evidence-based medicine: pressure sores. Plast Reconstr Surg. 2013;132(6):1720-1732. doi:10.1097/ PRS.0b013e3182a808ba

32. Graves N, Birrell F, Whitby M. Effect of pressure ulcers on length of hospital stay. Infect Control Hosp Epidemiol. 2005;26(3):293-297. doi:10.1086/502542

33. Cervelli V, De Angelis B, Lucarini L, et al. Tissue regeneration in loss of substance on the lower limbs through use of platelet-rich plasma, stem cells from adipose tissue, and hyaluronic acid. $A d v$ Skin Wound Care. 2010;23(6):262-272. doi:10.1097/01. ASW.0000363551.82058.36

34. de Leon JM, Driver VR, Fylling CP, et al. The clinical relevance of treating chronic wounds with an enhanced near-physiological concentration of platelet-rich plasma gel. Adv Skin Wound Care. 2011;24 (8):357-368. doi:10.1097/01.ASW.0000403249.85131.6f

35. Sell SA, Ericksen JJ, Reis TW, Droste LR, Bhuiyan MBA, Gater DR. A case report on the use of sustained release platelet-rich plasma for the treatment of chronic pressure ulcers. J Spinal Cord Med. 2011;34 (1):122-127. doi:10.1179/107902610X12923394765616

36. Liu Q, Zhang N, Li Z, He H. Efficacy of autologous platelet-rich plasma gel in the treatment of refractory pressure injuries and its effect on wound healing time and patient quality of life. Clinics. 2021;76:1-7. doi:10.6061/clinics/2021/e2355

37. Ministerio de Sanidad-servicios sociales e igualdad de España. Informe de La Agencia Española de Medicamentos y Productos Sanitarios Sobre El Uso de Plasma Rico En Plaquetas. 2013:1-5

38. Martinez-Zapata MJ, Martí-Carvajal AJ, Solà I, et al. Autologous platelet-rich plasma for treating chronic wounds. Cochrane Database Syst Rev. 2012;10(10):CD006899. doi:10.1002/14651858.CD006899. pub2

39. Lee H-W, Reddy MS, Geurs N, et al. Efficacy of platelet-rich plasma on wound healing in rabbits. J Periodontol. 2008;79(4):691-696. doi:10.1902/jop.2008.070449

40. Pietramaggiori G, Kaipainen A, Czeczuga JM, Wagner CT, Orgill DP. Freeze-dried platelet-rich plasma shows beneficial healing properties in chronic wounds. Wound Repair Regen. 2006;14(5):573-580. doi:10.1111/j.1743-6109.2006.00164.x

41. Pietramaggiori G, Scherer SS, Mathews JC, et al. Healing modulation induced by freeze-dried platelet-rich plasma and micronized allogenic dermis in a diabetic wound model. Wound Repair Regen. 2007;16(2):218-225. doi:10.1111/j.1524-475X.2008.00362.x

42. Pietramaggiori G, Scherer SS, Mathews JC, et al. Quiescent platelets stimulate angiogenesis and diabetic wound repair. J Surg Res. 2010;160(1):169-177. doi:10.1016/j.jss.2008.09.010

43. Takikawa M, Nakamura S-I, Nakamura S, et al. Enhancement of vascularization and granulation tissue formation by growth factors in human platelet-rich plasma-containing fragmin/protamine microparticles. J Biomed Mater Res B Appl Biomater. 2011;97(2):373-380. doi:10.1002/jbm.b.31824

44. Bir SC, Esaki J, Marui A, et al. Angiogenic properties of sustained release platelet-rich plasma: characterization in-vitro and in the ischemic hind limb of the mouse. J Vasc Surg. 2009;50(4):870-879. e2. doi:10.1016/j.jvs.2009.06.016 
45. DeRossi R, de O Coelho ACA, de Mello GS, et al. Effects of plateletrich plasma gel on skin healing in surgical wound in horses. Acta Cir Bras. 2009;24(4):276-281.

46. Iacono E, Merlo B, Pirrone A, et al. Effects of mesenchymal stem cells isolated from amniotic fluid and platelet-rich plasma gel on severe decubitus ulcers in a septic neonatal foal. Res Vet Sci. 2012;93(3):1439-1440. doi:10.1016/j.rvsc.2012.04.008

47. Molina-Miñano F, López-Jornet P, Camacho-Alonso F, VicenteOrtega V. The use of plasma rich in growth factors on wound healing in the skin: experimental study in rabbits. Int Wound J. 2009;6 (2):145-148. doi:10.1111/j.1742-481X.2009.00592.x

48. Dionyssiou D, Demiri E, Foroglou P, et al. The effectiveness of intralesional injection of platelet-rich plasma in accelerating the healing of chronic ulcers: an experimental and clinical study. Int Wound J. 2013;10(4):397-406. doi:10.1111/j.1742-481X.2012.00996.x

49. Ramos-Torrecillas J, García-Martínez O, De Luna-bertos E, OcañaPeinado FM, Ruiz C. Effectiveness of platelet-rich plasma and hyaluronic acid for the treatment and care of pressure ulcers. Biol Res Nurs. 2014. doi:10.1177/1099800414535840

50. Salcido RS. Autologous platelet-rich plasma in chronic wounds. $A d v$ Skin Wound Care. 2013;26(6):248. doi:10.1097/01.ASW.0000 430666.20897.c0

51. Moraes VY, Lenza M, Tamaoki MJ, Faloppa F, Belloti JC. Plateletrich therapies for musculoskeletal soft tissue injuries. Cochrane Database Syst Rev. 2014;4(4):CD010071. doi:10.1002/14651858. CD010071.pub3
52. Carter MJ, Fylling CP, Parnell LKS. Use of platelet rich plasma gel on wound healing: a systematic review and meta-analysis. Eplasty. 2011;11:e38.

53. Matras $H$. The use of fibrin sealant in oral and maxillofacial surgery. J Oral Maxillofac Surg. 1982;40(10):617-622.

54. Mishra A. Platelet-rich plasma. Orthopedics. 2010;33(7):486-487. doi:10.3928/01477447-20100526-13

55. Del Fabbro M, Bortolin M, Taschieri S. Is autologous platelet concentrate beneficial for post-extraction socket healing? A systematic review. Int $J$ Oral Maxillofac Surg. 2011;40(9):891-900. doi:10.1016/j.ijom.2011.04.009

56. Antonello GDM, Torres Do Couto R, Giongo CC, Corrêa MB, Chagas OL Júnior, Lemes CHJ. Evaluation of the effects of the use of platelet-rich plasma (PRP) on alveolar bone repair following extraction of impacted third molars: prospective study. $J$ Craniomaxillofac Surg. 2013;41(4):e70-5. doi:10.1016/j.jcms.201 2.11.003

57. Sommeling CE, Heyneman A, Hoeksema H, Verbelen J, Stillaert FB, Monstrey S. The use of platelet-rich plasma in plastic surgery: a systematic review. J Plast Reconstr Aesthet Surg. 2013;66(3):301311. doi:10.1016/j.bjps.2012.11.009

58. Guarín-Corredor C, Quiroga-Santamaría P, Landinez-Parra NS. Proceso de cicatrización de heridas de piel, campos endógenos y su relación con las heridas crónicas. Rev Fac Med. 2013;61(4 SE):441448 .
International Medical Case Reports Journal

\section{Publish your work in this journal}

The International Medical Case Reports Journal is an international, peer-reviewed open-access journal publishing original case reports from all medical specialties. Previously unpublished medical posters are also accepted relating to any area of clinical or preclinical science. Submissions should not normally exceed 2,000 words or 4

\section{Dovepress}

published pages including figures, diagrams and references. The manuscript management system is completely online and includes a very quick and fair peer-review system, which is all easy to use. Visit http://www.dovepress.com/testimonials.php to read real quotes from published authors. 